\title{
Posterior reversible encephalopathy syndrome- associated bilateral cortical blindness as presenting feature of severe pre-eclampsia
}

\author{
Shalaka Waghamare, ${ }^{1}$ Aarzoo Juneja, ${ }^{1}$ Ramanuj Samanta (D) , ${ }^{1}$ Amrita Gaurav ${ }^{2}$
}

${ }^{1}$ Ophthalmology, All India Institute of Medical SciencesRishikesh, Rishikesh, India ${ }^{2}$ Obstetrics and Gynaecology, All India Institute of Medical Sciences-Rishikesh, Rishikesh, India

\section{Correspondence to} Dr Ramanuj Samanta; ramanuj.samanta@gmail.com

Accepted 8 July 2021

\section{DESCRIPTION}

A 24 -year-old primigravida (gravida 1, para 0), at 34 weeks of gestation, presented to the emergency department of our hospital with a sudden painless bilateral visual loss for 1 day associated with mild headache. She did not have any history of loss of consciousness, trauma, seizure, fever, hypertension, diabetes, thyroid disorder or any cardiovascular diseases. Her antenatal history was insignificant. Ocular examination revealed visual acuity of only light perception and intact pupillary light responses in both eyes. Fundus (figure 1A,B) was unremarkable bilaterally, except a single dot haemorrhage temporal to the fovea in the right eye. No disc oedema, retinal detachment or any retinal vascular abnormality was noted in either eye. Optical coherence tomography (figure 1C,D) showed bilateral normal foveal contour and retinal nerve fibre layer thickness. Her blood pressure was found to be $170 / 100 \mathrm{~mm} \mathrm{Hg}$, recorded multiple times. Obstetrical examinations including fetal assessment and other systemic evaluations were normal. Laboratory investigations including complete haemogram, liver function test, renal function test, serum electrolytes and coagulation profile were unremarkable, except hypocalcaemia $(6.5 \mathrm{mg} / \mathrm{dL})$ and raised serum alkaline phosphatase levels $(454.8 \mathrm{U} / \mathrm{L})$. Urinalysis revealed $2+$ proteinuria and elevated levels of 24-hour urinary protein. Considering severe

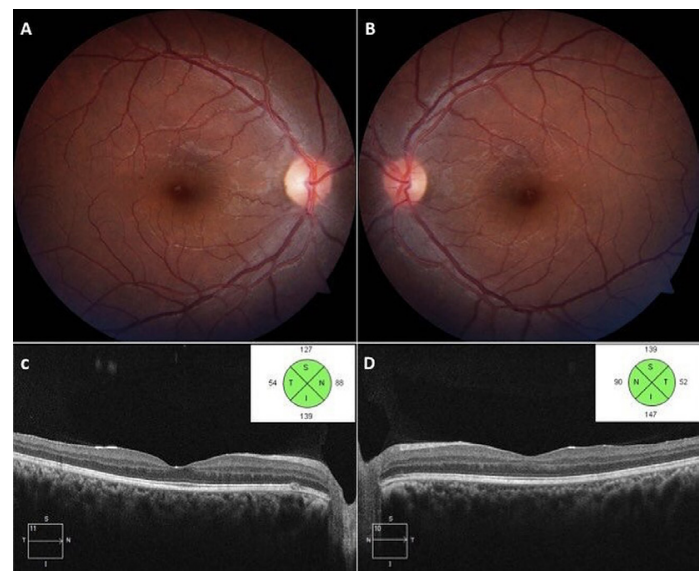

Figure 1 Fundus photograph of both eyes $(A, B)$ showing normal fundus except tiny retinal haemorrhage temporal to the fovea in the right eye. Optical coherence tomography demonstrating normal foveal contour $(C, D)$ with insets showing normal retinal nerve fibre layer thickness bilaterally.

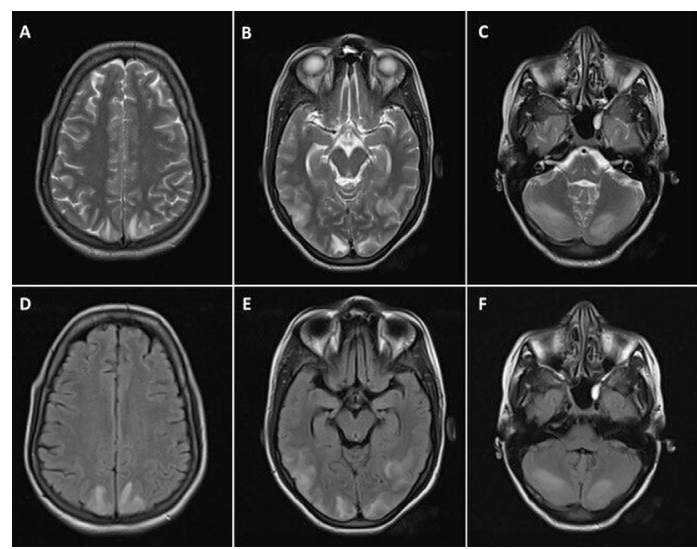

Figure 2 Brain MRI showing hyperintensities on T2weighted images and fluid-attenuated inversion recovery images in bilateral parietal ( $A$ and $D)$, occipital ( $B$ and $E$ ) and cerebellar hemispheres ( $C$ and $F$ ).

pre-eclampsia, treatment with magnesium sulfate (according to Pritchard regimen) and antihypertensive medication (labetalol) was initiated. An urgent MRI of the brain with venography revealed areas of T2/fluid-attenuated inversion recovery hyperintensities (figure 2A-F) in bilateral parieto-occipital lobes and cerebellar hemispheres, suggesting posterior reversible encephalopathy syndrome (PRES). A diagnosis of bilateral cortical blindness due to severe pre-eclampsia-associated PRES (PE-PRES) was made, and an emergency caesarean section was performed. The perinatal period was uneventful with a healthy mother and child. One week postoperatively, her visual acuity gradually restored to 20/20 in both eyes.

Pre-eclampsia and eclampsia are among the most common conditions associated with PRES, others being blood pressure fluctuations, renal failure, autoimmune diseases, cytotoxic drugs and organ transplants. PRES is characterised by reversible vasogenic cerebral oedema, often presenting with seizures, encephalopathy, headache or visual disturbances. ${ }^{1} 2$ Various mechanisms, including failure of cerebral autoregulation, endothelial injury by sudden blood pressure changes and direct cytokine effects on endothelium, have been postulated. All of these factors can lead to blood-brain barrier breakdown and consequent brain oedema. ${ }^{1}$

As parietal and occipital lobes are preferentially involved, visual symptoms are common in PRES. Lifson et al have reported visual complaints in $27 \%$ of patients diagnosed with PRES. ${ }^{3}$ However, 
clinical presentations in PE-PRES may vary from PRES due to other causes. PE-PRES was reported to have a higher prevalence of headache, less prevalence of altered mental status, equal prevalence of seizures and visual disturbances, less severe presentation and relatively better outcome than PRES due to other aetiologies. On neuroimaging also, patients with PE-PRES demonstrated less severe oedema, haemorrhage and contrast enhancement at presentation. More frequent resolution of oedema and less frequent residual structural lesions were noted on follow-up imaging in this category. ${ }^{4}$

Cortical blindness and serous retinal detachment are two important causes of reversible severe visual loss in preeclampsia. ${ }^{5-7}$ The visual loss in PRES is usually regained with

\section{Patient's perspective}

I was extremely scared when I lost vision in both eyes suddenly and I thought I would never regain vision. However, I did not have any major problem or illnesses during my pregnancy. On examination by a team of doctors, I came to know that my blood pressure is raised and was advised some medications with immediate caesarean section. They also assured me that my vision is likely to improve following childbirth. Fortunately, I regained my vision in about a week after surgery.

\section{Learning points}

- Posterior reversible encephalopathy syndrome-associated bilateral cortical blindness may be the initial presenting feature of pre-eclampsia.

- Simple bedside fundus evaluation and urgent brain MRI are the mainstay of diagnosis.

- Rapid and complete visual recovery may take place with definitive management of pre-eclampsia. the treatment of the predisposing cause. ${ }^{35}$ This report depicts an uncommon PRES-associated severe visual loss as the sole initial presenting feature of severe pre-eclampsia. Immediate bedside fundus evaluation, urgent neuroimaging and standard management of pre-eclampsia led to complete visual recovery within a week.

Acknowledgements The authors thank the patient, and the department(s) of obstetrics \& gynaecology, ophthalmology, radiology and neurology of the institute.

Contributors SW-data interpretation, first drafting of the manuscript and approval of the final version of the manuscript. AJ-data acquisition, drafting of the manuscript and approval of the final version of the manuscript. RS - design of the study, data interpretation, critical revision of the manuscript and approval of the fina version of the manuscript. AG—critical revision of the manuscript and approval of the final version of the manuscript.

Funding The authors have not declared a specific grant for this research from any funding agency in the public, commercial or not-for-profit sectors.

Competing interests None declared.

Patient consent for publication Obtained.

Provenance and peer review Not commissioned; externally peer reviewed.

\section{ORCID iD}

Ramanuj Samanta http://orcid.org/0000-0002-9737-8346

\section{REFERENCES}

1 Fugate JE, Rabinstein AA. Posterior reversible encephalopathy syndrome: clinical and radiological manifestations, pathophysiology, and outstanding questions. Lancet Neurol 2015;14:914-25.

2 McDermott M, Miller EC, Rundek T, et al. Preeclampsia: association with posterior reversible encephalopathy syndrome and stroke. Stroke 2018;49:524-30.

3 Lifson N, Pasquale A, Salloum G, et al. Ophthalmic manifestations of posterior reversible encephalopathy syndrome. Neuroophthalmology 2019;43:180-4.

4 Liman TG, Bohner G, Heuschmann PU, et al. Clinical and radiological differences in posterior reversible encephalopathy syndrome between patients with preeclampsiaeclampsia and other predisposing diseases. Eur J Neurol 2012;19:935-43.

5 Radha Bai Prabhu T, Prabhu TR. Serious visual (ocular) complications in pre-eclampsia and eclampsia. J Obstet Gynaecol India 2017;67:343-8.

6 Jayaraj S, Samanta R, Puthalath AS, et al. Pre-Eclampsia associated bilateral serous retinal detachment. BMJ Case Rep 2020;13:e238358.

7 Thackeray EM, Tielborg MC. Posterior reversible encephalopathy syndrome in a patient with severe preeclampsia. Anesth Analg 2007;105:184-6.

Copyright 2021 BMJ Publishing Group. All rights reserved. For permission to reuse any of this content visit

https://www.bmj.com/company/products-services/rights-and-licensing/permissions/

BMJ Case Report Fellows may re-use this article for personal use and teaching without any further permission.

Become a Fellow of BMJ Case Reports today and you can:

- Submit as many cases as you like

- Enjoy fast sympathetic peer review and rapid publication of accepted articles

- Access all the published articles

Re-use any of the published material for personal use and teaching without further permission

Customer Service

If you have any further queries about your subscription, please contact our customer services team on +44 (0) 2071111105 or via email at support@bmj.com.

Visit casereports.bmj.com for more articles like this and to become a Fellow 